\title{
Preparation of Tetrafluoroethylene from the Pyrolysis of Pentafluoropropionate Salts
}

Daniel A. Hercules ${ }^{\mathrm{a}}$, Cameron A. Parrish ${ }^{\mathrm{a}}$, Todd S. Sayler ${ }^{\mathrm{b}}$, Kevin T. Tice ${ }^{\mathrm{b}}$, Shane M. Williams ${ }^{\mathrm{a}}$, Lauren E. Lowery ${ }^{\mathrm{a}}$, Michael E. Brady ${ }^{\mathrm{a}}$, Robert B. Coward ${ }^{\mathrm{c}}$, Justin A. Murphy ${ }^{\mathrm{c}}$, Trevyn A. Hey ${ }^{\mathrm{c}}$, Anthony R. Scavuzzo ${ }^{a}$, Lucy M. Rummler ${ }^{\mathrm{d}}$, Emory G. Burns ${ }^{\mathrm{a}}$, Andrej V. Mastnev ${ }^{\mathrm{a}, \mathrm{b}}$, Richard E. Fernandez $^{\mathrm{a}, \mathrm{b}}$, Colin D. McMillen, ${ }^{\mathrm{a}}$ and Joseph S. Thrasher ${ }^{\mathrm{a}, \mathrm{b} *}$

${ }^{a}$ Department of Chemistry, Clemson University, Advanced Materials Research Laboratory, 91 Technology Drive, Anderson, SC 29625, USA., thrash5@clemson.edu, 001-864-656-5773.

${ }^{b}$ Department of Chemistry, University of Alabama, Box 870336, Tuscaloosa, AL 35487, USA.

${ }^{c}$ Department of Materials Science and Engineering, Clemson University, Clemson, SC 29634, USA.

${ }^{d}$ Department of Genetics and Biochemistry, Clemson University, Clemson, SC 29634, USA.

In honor of Professor Steven H. Strauss being the 2016 recipient of the American Chemical Society Award for Creative Work in Fluorine Chemistry

\begin{abstract}
The use of tetrafluoroethylene (TFE) in academic institutions beyond a few millimoles has often been inhibited by the compound's inherent danger and general lack of commercial availability. On the other hand, TFE is prepared industrially on a rather large scale by a number of major fluorochemical companies via the pyrolysis of chlorodifluoromethane at high temperatures, yielding TFE and $\mathrm{HCl}$. For a few years at The University of Alabama and Clemson University, we have been preparing TFE on a $100^{+}$-gram scale by the pyrolysis under dynamic vacuum of pentafluoropropionate salts, which can be obtained from the neutralization of pentafluoropropionic acid with a $\mathrm{M}(\mathrm{OH})_{\mathrm{n}}$ (where $\mathrm{M}=\mathrm{Li}, \mathrm{Na}, \mathrm{K}$, and $\mathrm{Cs}$ for $n=1$ and $\mathrm{Mg}, \mathrm{Ca}$, and $\mathrm{Ba}$ for $n=2$ ). Additionally, potassium pentafluoropropionate can be prepared from the reaction of potassium trimethylsilanolate and ethyl pentafluoropropionate. The pentafluoropropionate salts and their
\end{abstract}


decomposition products have been characterized by thermogravimetric analysis (TGA), differential scanning calorimetry (DSC), accelerating rate calorimetry (ARC), nuclear magnetic resonance (NMR) spectroscopy, mass spectrometry, Fourier transform-infrared (FTIR) spectrophotometry, scanning electron microscopy (SEM) / energy dispersive spectroscopy (EDAX), X-ray diffraction (XRD), and single-crystal X-ray crystallography, where applicable. Typical yields of TFE obtained from pyrolysis of potassium pentafluoropropionate obtained from the acid-base neutralization method are $>98 \%$, while yields of TFE from the same salt prepared by the silanolate method from ethyl pentafluoropropionate are ca. $80 \%$.

\section{Graphical Abstract}

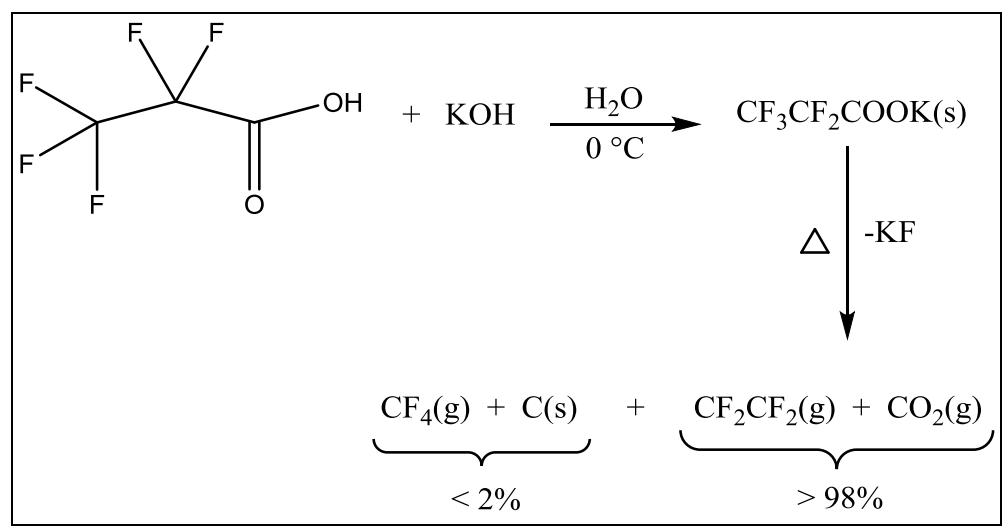


Keywords: tetrafluoroethylene (TFE); tetrafluoroethylene-carbon dioxide mixture; synthesis and pyrolysis of potassium pentafluoropropionate; use of TFE in academic institutions.

\section{Introduction}

Since the curious discovery of polytetrafluoroethylene (PTFE) in 1938 by Plunkett [1], the interest and use of tetrafluoroethylene (TFE) as a building block for fluoropolymers has increased due to the unique properties of materials that are made from this monomer. Its homopolymer has the advantages of being both chemically and thermally resistant, which are of great benefit for its use in aeronautics, parts manufacturing, and specialty materials [1]. Other compositions of matter of great importance can be derived from TFE such as its copolymers with various perfluoroalkyl vinyl ethers to give perfluoroalkoxy resins (PFA), with hexafluoropropylene to give fluorinated ethylene-propylene (FEP) resins, and with ethylene forming poly(ethylene-co-tetrafluoroethylene) (ETFE) [2]. Another major use of TFE is in the manufacture of perfluorinated ionomers such as Nafion $^{\circledR}$, Aquivion ${ }^{\circledR}$, and others for applications in the chlor-alkali industry as well as energy conversion and storage devices [3].

The fluorochemical industry prepares TFE via pyrolysis of chlorodifluoromethane $\left(\mathrm{CHClF}_{2}\right)$, more commonly known as $\mathrm{R} 22$, as shown in equation 1 . The advantage of this process is the ability to obtain TFE from $99.99 \%$ to $99.999 \%$ purity, but we have been led to believe that this synthetic method is impractical to be built on a smaller scale for an academic institution due to prohibitive cost and the inherent complications of running a continuous process without interruption [4]. 


$$
2 \mathrm{CHClF}_{2}(g) \longrightarrow \mathrm{C}_{2} \mathrm{~F}_{4}+2 \mathrm{HCl}(g)
$$

In addition to being able to prepare adequate quantities of TFE, a facility for the safe handling of TFE represents the other primary hurdle that an academic institution must overcome [5] when trying to prepare research quantities of TFE-based homo-, co-, and terpolymers. Thus, both at the University of Alabama [6] and more recently at Clemson University, we have constructed special facilities for the safe handling and polymerization of TFE. Until now, large quantities of TFE have been deemed too unsafe to be handled in an academic institution [7]. However, with the use of the aforementioned facilities, especially the most recent and advanced one at Clemson, the ability to handle TFE has been increased to the kilogram scale, while the storage of multi-kilogram quantities of TFE has also been enabled. These facilities, including a former TFE barricade at Clemson that was constructed by DesMarteau, were the subject of a recent review chapter [5].

For a number of years, TFE has not been commercially available with the exception of small quantities from an occasional catalog chemical company (e.g., ABCR GmbH), and even then the price is prohibitively high for the scale being described. Thus, we had to come up with a way to prepare TFE in our own laboratories. A common alternative to the industrial route to TFE is to actually pyrolyze waste PTFE; however, until recently, this method had been fraught with significant quantities of side products including hexafluoropropylene (HFP), octafluorocyclobutane (OFCB), and the extremely toxic perfluoroisobutylene (PFIB) [8]. Moreover, unless one has ready access to waste or scrap PTFE, this method may not be cost effective. 
While at the University of Alabama, an additional safety requirement existed due to the fact that the barricade facility there had been both incorrectly designed and built (i.e., too weak walls and floor to contain a deflagration of less than $125 \mathrm{~g}$ of TFE without structural damage). In order to use that facility, we turned to technology developed by the DuPont Company (now Chemours) where Van Bramer, Shiflett, and Yokozeki found that TFE could be rendered safe from deflagration when mixed with 30-mol \%, or more, carbon dioxide, $\mathrm{CO}_{2}$ [9]. Since this patent claimed only the liquid composition of $\mathrm{TFE} / \mathrm{CO}_{2}$, we made sure to use/store only gaseous mixtures of TFE/CO $\mathrm{CO}_{2}$ until the patent expired.

However, even with the additional safety feature in hand at least theoretically, a source of $\mathrm{TFE} / \mathrm{CO}_{2}$ was still required, as DuPont (now Chemours) only sells its TFE Safe - Supply ${ }^{\mathrm{TM}}$ to its commercial partners [10]. Interestingly enough, in the early 1950s both 3M and Haszeldine independently discovered that the pyrolysis of either alkali metal or alkaline earth metal pentafluoroalkanoate salts gave terminal perfluoroolefins and carbon dioxide in approximately equimolar mixtures as shown in equation 2 [11,12]. In their publications, $3 \mathrm{M}$ gave the most examples and obtained the best yields (96-99\%) for the generation of HFP when $n=1$ in equation 2. Researchers at $3 \mathrm{M}$ and Haszeldine both seemed to favor sodium as the alkali metal of choice for this reaction, and for the preparation of TFE (where $n=0$ in equation 2 ), they both obtained ca. $80-90 \%$ yield. Likewise, during the process of coming up to speed in terms of preparing TFE-

$$
\mathrm{C}_{\mathrm{n}} \mathrm{F}_{2 \mathrm{n}+1} \mathrm{CF}_{2} \mathrm{CF}_{2} \mathrm{C}(\mathrm{O}) \mathrm{OM} \longrightarrow \mathrm{C}_{\mathrm{n}} \mathrm{F}_{2 \mathrm{n}+1} \mathrm{CF}=\mathrm{CF}_{2}+\mathrm{CO}_{2}+\mathrm{MF}
$$

based fluoropolymers, we learned that Kornath and Kaufmann at the Ludwig-MaximiliansUniversität Munich had rediscovered this route to TFE and $\mathrm{CO}_{2}$, where they too seem to have a 
preference for the pyrolysis of the sodium salt. Admittedly, we learned and benefitted from their shared procedure [13].

More recently, our laboratory developed a process that demonstrates the importance of equimolar $\mathrm{TFE} / \mathrm{CO}_{2}$ mixtures not only for the preparation of fluoropolymers but also for small molecule chemistry, in particular for the synthesis of $\mathrm{SF}_{5}$-containing compounds. Thus, it was found that the 50:50 molar mixture of $\mathrm{TFE} / \mathrm{CO}_{2}$ could be safely converted into pentafluorosulfanyldifluoroacetic acid $\left[\mathrm{SF}_{5} \mathrm{CF}_{2} \mathrm{C}(\mathrm{O}) \mathrm{OH}\right]$ over four steps in about $60 \%$ overall yield. All earlier known approaches to $\mathrm{SF}_{5} \mathrm{CF}_{2} \mathrm{C}(\mathrm{O}) \mathrm{OH}$ were either significantly lower yielding processes or required the use of dangerous reagents, such as alkyl trifluorovinyl ethers or uninhibited TFE. The use of $\mathrm{TFE} / \mathrm{CO}_{2}$ mixtures allowed us to both prepare $\mathrm{SF}_{5} \mathrm{CF}_{2} \mathrm{C}(\mathrm{O}) \mathrm{OH}$ on a multi-gram scale as well as explore the chemistry of the $\mathrm{SF}_{5} \mathrm{CF}_{2^{-}}$group in the synthesis of compounds that might be of interest to medicinal and agro chemistry [14].

In the present report, support will be provided for the preference of potassium pentafluoropropionate as the starting material of choice for preparing mixtures of TFE and $\mathrm{CO}_{2}$. The reasons include, among others, (1) an increased overall yields of TFE and $\mathrm{CO}_{2}$, (2) a more even control of heat and mass transfer during the pyrolysis, and (3) less foaming during the pyrolysis. The simple neutralization of pentafluoropropionic acid, $\mathrm{CF}_{3} \mathrm{CF}_{2} \mathrm{C}(\mathrm{O}) \mathrm{OH}$, with potassium hydroxide, $\mathrm{KOH}$, to give potassium pentafluoropropionate will also be preferred over the reaction of the corresponding ethyl ester $\mathrm{CF}_{3} \mathrm{CF}_{2} \mathrm{C}(\mathrm{O}) \mathrm{OCH}_{2} \mathrm{CH}_{3}$ with potassium trimethylsilanolate, $\left(\mathrm{CH}_{3}\right)_{3} \mathrm{SiOK}$ [15]. Evidence for the formation of carbon, $\mathrm{C}$, and tetrafluoromethane, $\mathrm{CF}_{4}$, as minor byproducts during the formation of TFE and $\mathrm{CO}_{2}$ in the pyrolysis of potassium pentafluoropropionate will also be presented. 


\section{Results and discussion}

We have incorporated former patent technology from both 3M [11c] and DuPont (now Chemours) [9] in the preparation and use of $\mathrm{TFE} / \mathrm{CO}_{2}$ mixtures. Two approaches can be used to prepare either alkali or alkaline earth metal pentafluoropropionates: (Method A) the slow neutralization of an aqueous metal hydroxide solution/slurry by pentafluoropropionic acid yielding water and the corresponding alkali or alkali earth metal pentafluoropropionate, as shown in equation 3, or (Method B) the corresponding reaction of a pentafluoropropionate ester with a metal silanolate in an organic solvent such as diethyl ether, as shown in equation 4. With Method A, pentafluoropropionic acid is added drop wise to a chilled, aqueous solution (or slurry) of base in order to prevent loss of acid due to evaporation from the heat of the reaction. The reaction mixture is titrated until slightly acidic, as any excess acid can easily be removed during the drying stages,

$$
\mathrm{CF}_{3} \mathrm{CF}_{2} \mathrm{C}(\mathrm{O}) \mathrm{OH}+\mathrm{KOH} \stackrel{0{ }^{\circ} \mathrm{C}}{\longrightarrow} \mathrm{CF}_{3} \mathrm{CF}_{2} \mathrm{C}(\mathrm{O}) \mathrm{OK}+\mathrm{H}_{2} \mathrm{O}
$$

$$
\begin{aligned}
& \mathrm{CF}_{3} \mathrm{CF}_{2} \mathrm{C}(\mathrm{O}) \mathrm{OCH}_{2} \mathrm{CH}_{3}+\left(\mathrm{CH}_{3}\right)_{3} \mathrm{SiOK} \stackrel{\mathrm{Et}_{2} \mathrm{O}}{\longrightarrow} \mathrm{CF}_{3} \mathrm{CF}_{2} \mathrm{C}(\mathrm{O}) \mathrm{OK}+\left(\mathrm{CH}_{3}\right)_{3} \mathrm{SiOCH}_{2} \mathrm{CH}_{3} \\
& \text { r.t., } 24 \mathrm{~h}
\end{aligned}
$$

where that would not be possible for excess base. While it was easy to obtain $98-99 \%$ yield of the corresponding metal pentafluoropropionate from the simple acid-base chemistry, we had trouble achieving the $92-93 \%$ literature yield $[15 \mathrm{a}, \mathrm{b}]$ of potassium pentafluoropropionate via the silanolate chemistry and only obtained the desired salt in $75-80 \%$ yield. Two possible explanations for the difference in percent yields are the choice of reaction solvent (previous results are reported using 
either THF, dioxane, diethyl ether, or $\mathrm{CH}_{2} \mathrm{Cl}_{2}$ [15]) and the molar ratio of the reactants used. For example, in a more recent and thorough study, Lovrić and co-workers used 1.2 molar equivalents of silanolate for every mole of ester [15c], where we carried out our reactions on an equimolar scale as described by the previous investigators [15a,b]. Furthermore, the silanolate route does not seem to be nearly as cost effective, and as will be described below, the pyrolysis of potassium pentafluoropropionate prepared by this route also gave far lower yields of TFE and $\mathrm{CO}_{2}$.

Another important step in the process of obtaining $\mathrm{TFE} / \mathrm{CO}_{2}$ in high yield and purity is the drying of the pentafluoropropionate salt. First, bulk water is removed using a rotary evaporator, and the resulting material is then ground to a fine powder with a mortar and pestle prior to exhaustive drying at $80{ }^{\circ} \mathrm{C}$ and $20 \mathrm{mT}$ Torr vacuum until the salts reach a constant weight. (The early literature indicates drying "by heating in air at $100^{\circ} \mathrm{C}$ for 8 hours" [11a].) If necessary, the salts can be ground again, but usually just shaking the material within the flask will break up any clumps that may have formed during further drying. The drying stages beyond the removal of bulk water are usually carried out both on the amount of salts that will be used in an upcoming pyrolysis as well as in what will become the pyrolysis flask so as to not have to transfer the material further. As will be shown further when the thermal properties of the pentafluoropropionate salts are discussed, it is extremely important to not overheat the salts while drying so as to avoid rapid gas evolution due to an unexpected onset of thermal decomposition. It is crucial to pay attention to this part of the drying process in an academic institution, especially if undergraduate students are involved. On the other hand, should residual water remain in the salts, the primary impurity previously found in the pyrolysis products, other than TFE and $\mathrm{CO}_{2}$, was pentafluoroethane $\left(\mathrm{CF}_{3} \mathrm{CF}_{2} \mathrm{H}, \mathrm{HFC}-125\right)[6 \mathrm{~b}, 11]$. 
The pentafluoropropionate salts, especially the potassium salt, were spectroscopically characterized by multinuclear NMR, infrared, and mass spectrometry. All spectra were as expected, with only the results of the negative ion, electrospray ionization (ESI) mass spectrometry bearing further comment. In the Experimental and Supporting Information sections, one will notice that many of the anion clusters observed in the ESI-mass spectra of potassium pentafluoropropionate have one or more sodium (Na) atoms present. Alkali metal salts are well known for not being metal pure, so perhaps the technical grade $\mathrm{KOH}$ used had some sodium contamination, and/or some sodium contamination came during the sample preparation, etc. Furthermore, other researchers have reported that the ESI-mass spectra of lariat ethers with carboxylate arms display a strong selectivity for sodium over potassium [16]. Both the thermal and crystal properties of the pentafluoropropionate salts will discussed below.

One of the primary reasons for our preference of using potassium pentafluoropropionate over sodium pentafluoropropionate turns out to be the fact that one can routinely prepare a mixture of TFE and $\mathrm{CO}_{2}$ in $98 \%$ yield with the potassium salt, where we and others $(3 \mathrm{M}$ and Haszeldine $[11,12])$ only achieved about $80-90 \%$ yield from the sodium salt. For comparison, it is important to note that researchers at $3 \mathrm{M}$ were able to obtain $98-99 \%$ yields of hexafluoropropylene (HFP) and $\mathrm{CO}_{2}$ when pyrolyzing sodium heptafluorobutyrate (see equation 2 for $n=1$ ) [11]. Haszeldine also appeared to carry out his pyrolysis at 150 Torr, which could have also led to more side products (e.g., perfluorocyclobutane, $\mathrm{C}_{4} \mathrm{~F}_{8}$ ). Perhaps this outcome is parallel to the observation that fewer impurities are obtained in the production of TFE when the pyrolysis of PTFE is carried out under more strongly reduced pressure [6]. In our hands, the pyrolysis of potassium pentafluoropropionate under a low heating rate of $1^{\circ} \mathrm{C}$ per minute from 80 to $300{ }^{\circ} \mathrm{C}$ and dynamic vacuum $\left(10^{-3}\right.$ to $10^{-4}$ Torr, with the gaseous products being collected at liquid nitrogen 
temperature) gave a mixture of TFE and $\mathrm{CO}_{2}$ with no discernible impurities by NMR and infrared spectroscopy. On the other hand, although the potassium pentafluoropropionate prepared by the silanolate method appeared spectroscopically to be the same as the potassium salt prepared by the simple neutralization reaction, its thermal decomposition gave $\mathrm{TFE}$ and $\mathrm{CO}_{2}$ in only about $75-80 \%$ yield. Overall, it is important to remember that regardless of the choices of metal cation and pyrolysis conditions, one obtains TFE with roughly equimolar amounts of $\mathrm{CO}_{2}$, which results in a safe gas mixture for handling [9] in further research.

We next turned our attention to the identification of the yield-loss products as well as any rationale for why the potassium salt gives higher yields of TFE and $\mathrm{CO}_{2}$. First, remaining after the pyrolysis of any pentafluoropropionate salt should be the corresponding white, metal fluoride, as shown by way of example for the potassium salt in equation 5. However, the salts remaining after

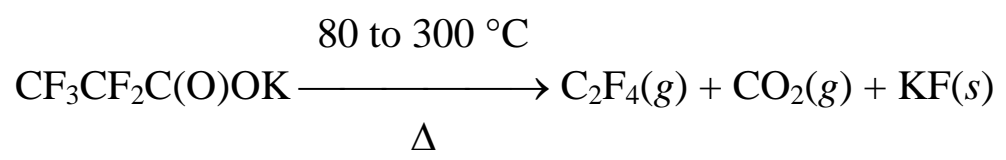

the pyrolysis of potassium pentafluoropropionate prepared by the neutralization reaction appeared to have dark-colored specks throughout them, while the salts remaining after the pyrolysis of either potassium pentafluoropropionate prepared by the silanolate method or sodium pentafluoropropionate appeared tan to light brown in color. Previously, Haszeldine had mentioned in the Experimental section of one of his papers that the pyrolysis of potassium pentafluoropropionate in addition to $\mathrm{TFE}, \mathrm{CO}_{2}$, and $\mathrm{KF}$ "gave a small amount of carbon" [12b], although no characterization/analytical method was given. As shown in Figure 1, we had the salts remaining from a number of pyrolysis experiments examined by scanning electron microscopy 
(SEM) / energy dispersive spectroscopy (EDAX), and clearly elemental carbon is present. Furthermore, when applying our normal heating rate of $1{ }^{\circ} \mathrm{C} / \mathrm{min}$, the amount of carbon found in the remaining salts was around 0.5 to $1.0 \mathrm{wt} \%$, but when applying a more rapid heating rate of $4{ }^{\circ} \mathrm{C} / \mathrm{min}, 1.5 \mathrm{wt} \%$ carbon or higher was found. The latter was typically the case for analyses of the salts remaining from the pyrolysis of either potassium pentafluoropropionate prepared by the silanolate method or sodium pentafluoropropionate. When comparing the observations from the

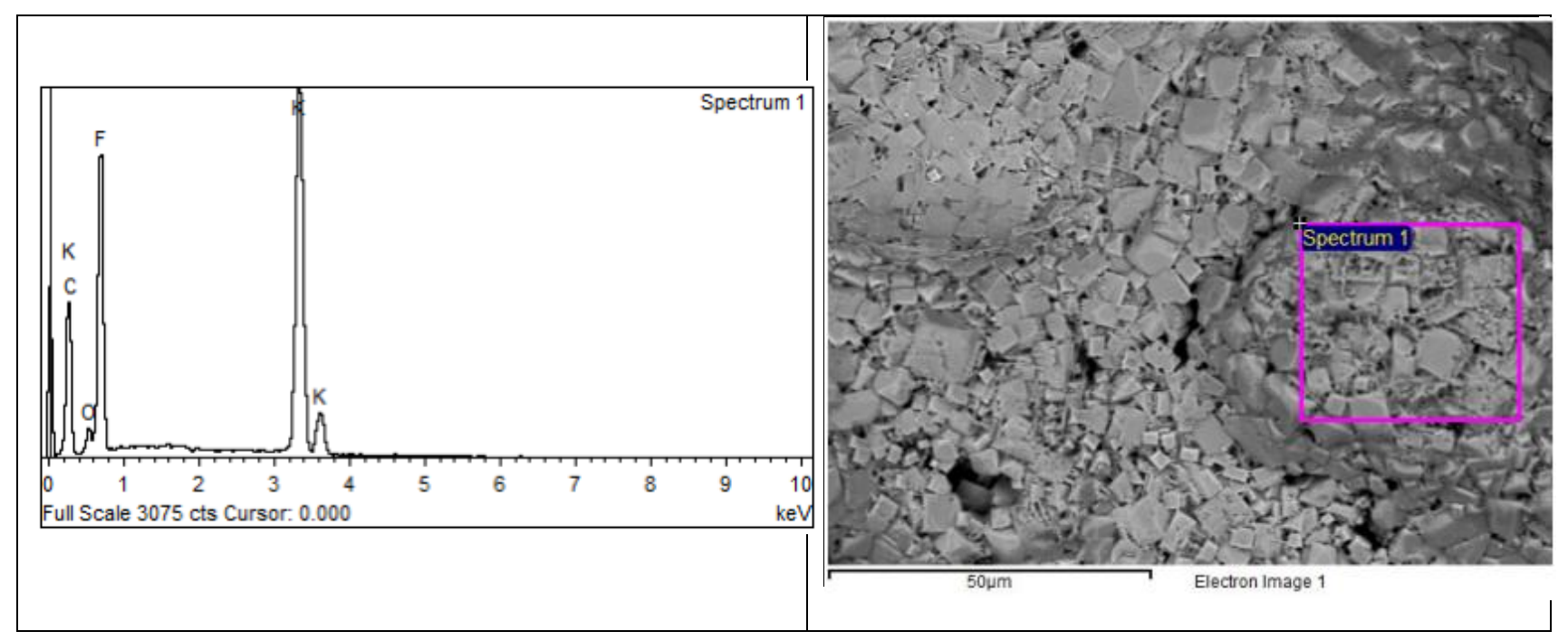

Figure 1. Left: X-ray elemental analysis of left over solids after pyrolysis showing the presence of elemental carbon. Right: Electron microscopy image of left over solids after pyrolysis.

EDAX experiments, the most likely source of elemental carbon would be the well-known, and undesired, disproportionation of TFE as shown in equation 6 [7]. If this is the case, then one should also be able to find evidence for the formation of carbon tetrafluoride.

$$
\mathrm{C}_{2} \mathrm{~F}_{4}(g) \rightarrow \mathrm{CF}_{4}(g)+\mathrm{C}(s) \Delta H_{R}=-276 \mathrm{~kJ} / \mathrm{mol}
$$


In fact, one experimental observation that has not yet been mentioned is that a slight rise in pressure of about 20-30 mTorr is observed during the actual period of thermal decomposition of each pentafluoropropionate salt on a thermocouple gauge tube that is placed between the main vacuum trap (held at $-196^{\circ} \mathrm{C}$ ) and the vacuum pump. This can only be indicative of either a small leak in the vacuum system or the generation of a small, but constant amount of a non-condensable gas. In fact, when the pyrolysis of the salts is complete, the reading of the thermocouple vacuum gauge comes back down to whatever the previous ultimate obtainable vacuum level of the system was prior to the pyrolysis. Having ruled out any leaks in the system during numerous experiments, only the generation of a small, but continuous amount of a non-condensable gas can be operative. Furthermore, $\mathrm{CF}_{4}$ is known to have a very small residue vapor pressure even at liquid nitrogen temperature [17]. We expended great effort trying to first obtain infrared spectroscopic evidence for the presence of $\mathrm{CF}_{4}$ by sampling the gases either coming directly off of the pyrolysis of the salts prior to the liquid nitrogen-cooled collection trap or coming through the liquid nitrogen trap, including warming this trap slightly in order to catch a representative sample of the most volatile products. In no case could we observe convincing evidence for the presence of $\mathrm{CF}_{4}$; an example of several overlaid FT-IR spectra of gases coming off a pyrolysis versus authentic spectra of samples of TFE and $\mathrm{CF}_{4}$ is shown in Figure $\mathrm{S} 11$ (cf. [18]). Thereafter, we moved to a more sensitive analytical technique, namely GC-mass spectrometry, including the use of selective ion monitoring (SIM). Use of the latter was chosen not only due to the enhanced sensitivity of the SIM mode, but also because a comparison of both literature [19] and experimental mass spectra of $\mathrm{CF}_{4}$ and TFE reveals a striking difference in the intensity of the $69 \mathrm{~m} / \mathrm{z}$ peak for $\mathrm{CF}_{3}{ }^{+}$. More specifically, the 69 $\mathrm{m} / \mathrm{z}$ peak is by far and away the base peak in the mass spectrum of $\mathrm{CF}_{4}$, while this peak is only about $4-5 \%$ relativity intensity versus the base peak at $81 \mathrm{~m} / \mathrm{z}$ for $\mathrm{C}_{2} \mathrm{~F}_{3}{ }^{+}$in TFE (when collecting 
data above $40 \mathrm{~m} / \mathrm{z}$ ). As shown in a series of mass spectra in the Supporting Information (see Figures S13-S15), the $69 \mathrm{~m} / \mathrm{z}$ peak in the aforementioned gas samples taken during the pyrolysis is approximately twice as intense as it is an authentic sample of TFE that has been degassed of any residual $\mathrm{CF}_{4}$. These observation collectively give the best evidence that we have to date for $\mathrm{CF}_{4}$ being a minor side product, along with carbon, in the thermal decomposition of pentafluoropropionate salts to generate a mixture of TFE and $\mathrm{CO}_{2}$.

Moving to the thermal properties of the pentafluoropropionate salts, we have already reported results on the accelerating rate calorimetry of the sodium, potassium, and calcium salts (see Figures S16-S18) [6]; however, and an overview of the results bears repeating here. First, the sample of sodium pentafluoropropionate appears to start slowly decomposing around $230{ }^{\circ} \mathrm{C}$ and does not finish decomposing until about 100 minutes later at about $260{ }^{\circ} \mathrm{C}$. Meanwhile, the sample of potassium pentafluoropropionate does not start decomposing as evidenced by rapid gas evolution until about $280{ }^{\circ} \mathrm{C}$, and the decomposition is complete within a few minutes before the sample reaches $300{ }^{\circ} \mathrm{C}$. However, a word of caution can be offered here, as a small exotherm, without significant gas evolution, is observed at a temperature as low as $175^{\circ} \mathrm{C}$. This is the reason for the earlier warning of not drying potassium pentafluoropropionate salts at too high of a temperature. The sample of calcium pentafluoropropionate exhibited a small endotherm and pressure increase at about $160{ }^{\circ} \mathrm{C}$, which could have been due to the elimination of water from a small amount of remaining hydrate. However, stronger decomposition and gas evolution did not occur until about $280{ }^{\circ} \mathrm{C}$ and continued for ca. 500 minutes to beyond $350{ }^{\circ} \mathrm{C}$. Collectively, the ARC results seem to indicate a preference for potassium pentafluoropropionate over the corresponding sodium and calcium salts [6]. No ARC experiment gave rise to a strong exotherm, which is consistent on one hand with the fact the thermal decomposition of these salts requires 
constant heat input until their decompositions are complete, i.e., their thermal decompositions are not exothermic enough whereby the heats of reaction generate sufficient energy to keep the decompositions proceeding once started. On the second hand, it is also important to note that the ARC results are in agreement with the DuPont (now Chemours) technology for 'safe TFE' as no deflagrations were observed under condition up to $400^{\circ} \mathrm{C}$ and $350 \mathrm{psig}$.

In hopes of learning more about the thermal properties of these materials, pentafluoropropionate salts of lithium, sodium, potassium, cesium, magnesium, calcium, and barium were prepared, dried, and studied by thermogravimetric analysis (TGA) even though researchers at 3M had carried out parallel studies back in the 1950s [11b]. The results are overviewed in Tables 1 and 2 and shown graphically in Figures S19-S34. As indicated by fewer ARC experiments, the data further confirm that higher decomposition temperatures are required for each of the divalent metal salts than those for all of the monovalent salts. On the other hand, no noticeable trends were observed based on cation size within either the alkali metal or the alkaline earth metal series of salts in terms of the concept of stabilization of a complex anion by a bulky cation, i.e., minimization of the lattice energy differences between the metal pentafluoropropionate and its corresponding metal fluoride by using a bulky cation [20]. Nevertheless, the TGA of potassium pentafluoropropionate displays step-like behavior (with weight loss versus increasing temperature and time) as indicated by an initial maximum rate of decomposition at $196{ }^{\circ} \mathrm{C}$ followed later by a second maximum rate of decomposition at $229{ }^{\circ} \mathrm{C}$. Interestingly, during this second decomposition step, the potassium salt shows the fastest rate of decomposition (i.e., gas evolution) at $3.82 \% /{ }^{\circ} \mathrm{C}$ of any of the pentafluoropropionate salts studied. While the cesium salt also displays this step-like decomposition, none of the alkaline earth metal salts did so as might have been expected from the ARC data on the calcium salt. 
Table 1. Thermogravimetric data analysis (TGA) for $\mathrm{CF}_{3} \mathrm{CF}_{2} \mathrm{C}(\mathrm{O}) \mathrm{O}^{-} \mathrm{M}^{+}$(where $\mathrm{M}=\mathrm{Li}^{+}, \mathrm{Na}^{+}, \mathrm{K}^{+}$, $\mathrm{Cs}^{+}, \mathrm{Mg}^{2+}, \mathrm{Ca}^{2+}$, or $\left.\mathrm{Ba}^{2+}\right)$.

\begin{tabular}{ccccc}
\hline Sample & $\begin{array}{c}\text { Temperature } \\
\text { at } 10 \% \text { mass } \\
\text { loss }\left({ }^{\circ} \mathrm{C}\right)\end{array}$ & $\begin{array}{c}\text { Mass } \% \\
\text { remaining } \\
\text { at end of } \\
\text { TGA }\end{array}$ & $\begin{array}{c}\text { Temperature at } \\
\text { maximum rate } \\
\text { decomposition }\left({ }^{\circ} \mathrm{C}\right)\end{array}$ & $\begin{array}{c}\text { Mass percent loss at } \\
\text { maximum rate } \\
\text { decomposition } \\
\left(\% /{ }^{\circ} \mathrm{C}\right)\end{array}$ \\
\hline $\mathrm{CF}_{3} \mathrm{CF}_{2} \mathrm{C}(\mathrm{O}) \mathrm{O}^{-} \mathrm{Li}^{+}$ & 258 & 14.44 & 281 & 2.81 \\
$\mathrm{CF}_{3} \mathrm{CF}_{2} \mathrm{C}(\mathrm{O}) \mathrm{O}^{-} \mathrm{Na}^{+}$ & 227 & 23.14 & 243 & 2.81 \\
$\mathrm{CF}_{3} \mathrm{CF}_{2} \mathrm{C}(\mathrm{O}) \mathrm{O}^{-} \mathrm{K}^{+}$ & $197 *$ & 28.96 & 196 and 229 & 1.25 and 3.82 \\
$\mathrm{CF}_{3} \mathrm{CF}_{2} \mathrm{C}(\mathrm{O}) \mathrm{O}^{-} \mathrm{Cs}^{+}$ & $208^{* *}$ & 52.95 & 205 and 236 & 1.17 and 3.31 \\
{$\left[\mathrm{CF}_{3} \mathrm{CF}_{2} \mathrm{C}(\mathrm{O}) \mathrm{O}^{-}\right]_{2} \mathrm{Mg}^{2+}$} & 298 & 17.52 & 331 & 2.79 \\
{$\left[\mathrm{CF}_{3} \mathrm{CF}_{2} \mathrm{C}(\mathrm{O}) \mathrm{O}^{-}\right]_{2} \mathrm{Ca}^{2+}$} & 324 & 21.83 & 345 & 2.77 \\
{$\left[\mathrm{CF}_{3} \mathrm{CF}_{2} \mathrm{C}(\mathrm{O}) \mathrm{O}^{-}\right]_{2} \mathrm{Ba}^{2+}$} & 290 & 33.55 & 321 & 2.37
\end{tabular}

Additionally, potassium pentafluoropropionate shows $3 \%$ mass loss at $130{ }^{\circ} \mathrm{C}$ and cesium pentafluoropropionate shows a $3 \%$ mass loss at $120^{\circ} \mathrm{C}$. *At this temperature, the compound is already decomposing rapidly (see SI for the detailed TGA analysis). **At this temperature, the compound is already decomposing rapidly (see SI for the TGA analysis).

Table 2. Mass percent of metal fluoride remaining at the end of each TGA - theoretical versus experimental.

\begin{tabular}{|c|c|c|c|c|c|}
\hline \multicolumn{2}{|l|}{ Sample } & \multicolumn{3}{|c|}{ Metal fluoride remaining (theoretical) } & \multirow{2}{*}{$\begin{array}{c}\text { Mass \% } \\
\text { remaining at the } \\
\text { end of each TGA } \\
\text { (experimental) }\end{array}$} \\
\hline Formula & $\begin{array}{l}\text { M.W. } \\
(\mathrm{g} / \mathrm{mol})\end{array}$ & Formula & $\begin{array}{l}\text { M.W. } \\
\text { (g/mol) }\end{array}$ & Mass \% & \\
\hline $\mathrm{CF}_{3} \mathrm{CF}_{2} \mathrm{C}(\mathrm{O}) \mathrm{OLi}^{+}$ & 169.96 & $\mathrm{LiF}$ & 25.94 & 15.26 & $14.44 *$ \\
\hline $\mathrm{CF}_{3} \mathrm{CF}_{2} \mathrm{C}(\mathrm{O}) \mathrm{O}^{-} \mathrm{Na}^{+}$ & 186.01 & $\mathrm{NaF}$ & 41.99 & 22.57 & 23.14 \\
\hline $\mathrm{CF}_{3} \mathrm{CF}_{2} \mathrm{C}(\mathrm{O}) \mathrm{O}^{-} \mathrm{K}^{+}$ & 202.12 & $\mathrm{KF}$ & 58.10 & 28.74 & 28.96 \\
\hline $\mathrm{CF}_{3} \mathrm{CF}_{2} \mathrm{C}(\mathrm{O}) \mathrm{O}^{-} \mathrm{Cs}^{+}$ & 295.93 & $\mathrm{CsF}$ & 151.91 & 51.33 & 52.95 \\
\hline$\left[\mathrm{CF}_{3} \mathrm{CF}_{2} \mathrm{C}(\mathrm{O}) \mathrm{O}^{-}\right]_{2} \mathrm{Mg}^{2+}$ & 350.35 & $\mathrm{MgF}_{2}$ & 62.30 & 17.78 & $17.52 *$ \\
\hline$\left[\mathrm{CF}_{3} \mathrm{CF}_{2} \mathrm{C}(\mathrm{O}) \mathrm{O}^{-}\right]_{2} \mathrm{Ca}^{2+}$ & 366.12 & $\mathrm{CaF}_{2}$ & 78.07 & 21.32 & 21.83 \\
\hline$\left[\mathrm{CF}_{3} \mathrm{CF}_{2} \mathrm{C}(\mathrm{O}) \mathrm{O}^{-}\right]_{2} \mathrm{Ba}^{2+}$ & 463.37 & $\mathrm{BaF}_{2}$ & 175.33 & 37.84 & $33.55^{*}$ \\
\hline
\end{tabular}

*Cases where the mass $\%$ of metal fluoride remaining at the end of an experiment is significantly less than theoretical may be due to blow off of some of the sample during gas evolution from the decomposition. 
At this point, we were still not satisfied with the existing rationale for why the thermal decomposition of potassium pentafluoropropionate gave better results, so we decided to film the thermal decompositions of bulk quantities of sodium and potassium pentafluoropropionate, which are normally carried out in our barricade facility [5] and had only been watched momentarily while filling liquid nitrogen baths around product (TFE and $\mathrm{CO}_{2}$ ) collection cylinders. Two, time-lapsed videos are provided as part of the supporting information, and they provide clear visual insight as for why potassium pentafluoropropionate should be preferred. First, the sodium salt clearly melts prior to any significant decomposition, and due to the better heat and mass transfer in a liquid (versus a solid), the reaction is rather rapid and violent. Lots of foaming is observed with the evolution of gases, which was the original reason for using long-necked flasks for the decomposition reactions [13]. The foaming is undoubtedly due to the well-known surfactant properties of sodium pentafluoropropionate [21], and the corresponding potassium salt would be expected to be an even better surfactant based on the larger cation. The remaining mass in the reaction flask from the thermal decomposition of sodium pentafluoropropionate only solidifies near the end of the thermal decomposition when the bulk material is nominally sodium fluoride; the brownish color, first of the melt and then the solid, is also clearly visible.

In the second video, one can clearly sees that the potassium pentafluoropropionate salts never truly melt. Instead, one sees what appears like a 'wetted' or slightly darker band of color move progressively across from the outer walls of the reaction flask toward the center of the flask. Clearly the salts that are in more direct contact with the outer walls of the reaction flask increase in temperature more rapidly than do the salts toward the center of the flask, as they are in closest proximity to the heat source. Even though the TGA and ARC experiments showed a more rapid gas evolution (thermal decomposition) of the potassium salt, these experiments were only done on 
the scales of milligrams to about a gram. When carried out on the scale of several hundred grams of material, the much poorer heat and mass transfer in a solid bed versus a melt helps mitigate or control the rate of thermal decomposition of potassium pentafluoropropionate. We feel that this situation results in an overall lower reaction pressure when the product gases are being trapped at liquid nitrogen temperature under dynamic vacuum and thus less unwanted side products are generated and a greater overall yield of TFE and $\mathrm{CO}_{2}$ is obtained.

Differential scanning calorimetry (in combination with TGA) was also run on both the sodium and potassium pentafluoropropionate salts (see Figures S35 and S36). Consistent with the videos, a strong endotherm for melting is seen for the sodium salt around $225{ }^{\circ} \mathrm{C}$ prior to thermal decomposition with a maximum heat flow around $275^{\circ} \mathrm{C}$, while the potassium salt shows a couple of weaker endotherms below $200{ }^{\circ} \mathrm{C}$, which may be due to some type of phase transitions in the solid state, prior to thermal decomposition with a maximum heat flow around $245{ }^{\circ} \mathrm{C}$.

In a final attempt to better understand why no dependence on cation size was found in the thermal studies of the pentafluoropropionate salts, we recently undertook a study of the powder and single crystal X-ray diffraction of these materials. Unfortunately, humid air could not be excluded during the collection of the powder data, so some of the materials undoubtedly absorbed water during the data collection, especially the lithium and magnesium salts [22]. In terms of growing single crystals, water has so far been the solvent of choice, but we have been fortunate to obtain acceptable data on non-hydrated crystals of both sodium and potassium pentafluoropropionate. Structures of hydrated crystals of magnesium and calcium pentafluoropropionate were also obtained, but these will be reported separately. The molecular structure of sodium pentafluoropropionate is shown below in Figure 2. No unusual bond distances or angles were found, and all of the tables of data corresponding to the structure solutions are 
shown in the Supporting Information. More important is to compare the coordination spheres around both sodium and potassium in the two structures as shown with the wire frame representations in Figure 3. As expected due to its smaller size, the sodium atom is six-coordinate, while the larger potassium atom is generally nine-coordinate (although other eight-, nine-, and tencoordinate potassium atoms exist in the complex unit cell of this structure; further details will appear separately). It is interesting to note that some of the pentafluoropropionate ligands filling the coordination spheres of the sodium and potassium atoms are not just monodentate but polydentate as well, and the coordination (or close contacts) is not just via the carboxylate oxygen atoms, but also sometimes through a fluorine atom. In fact, in sodium pentafluoropropionate, the short contacts involving fluorine atoms are always to an $\alpha$-fluorine atom, while in potassium

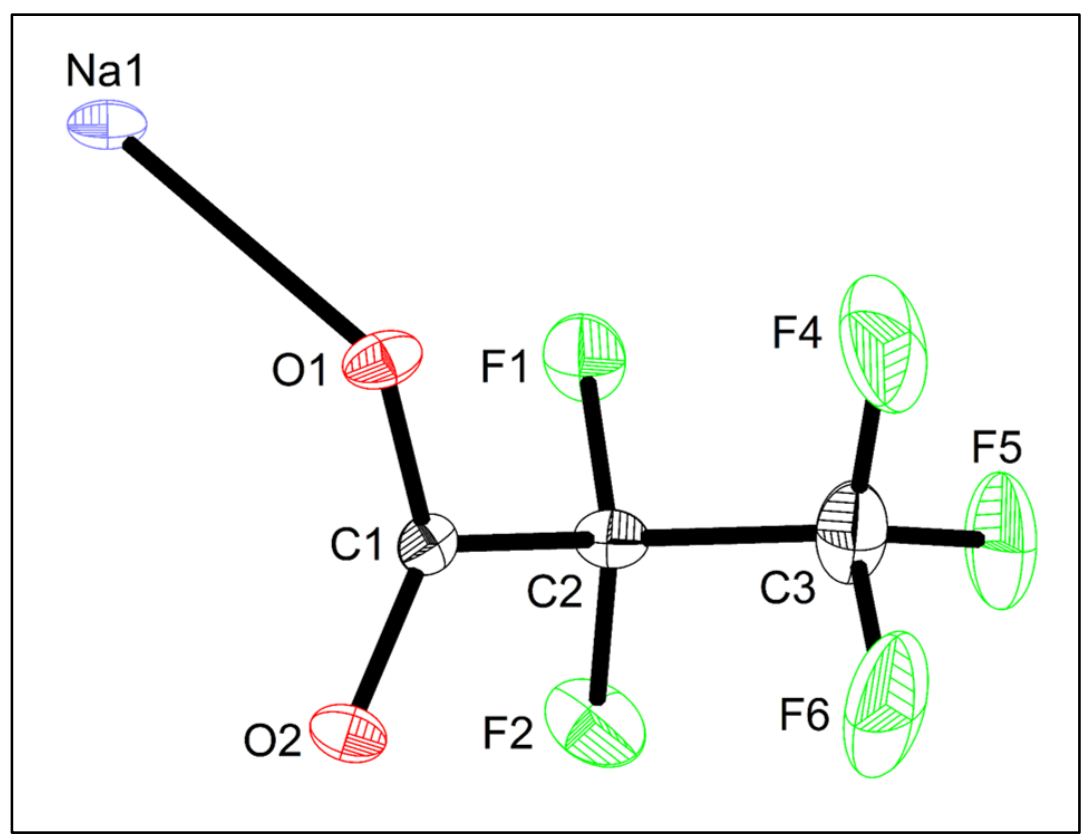

Figure 2. OPRTEP representation of sodium pentafluoropropionate (50\% probability ellipsoids). 

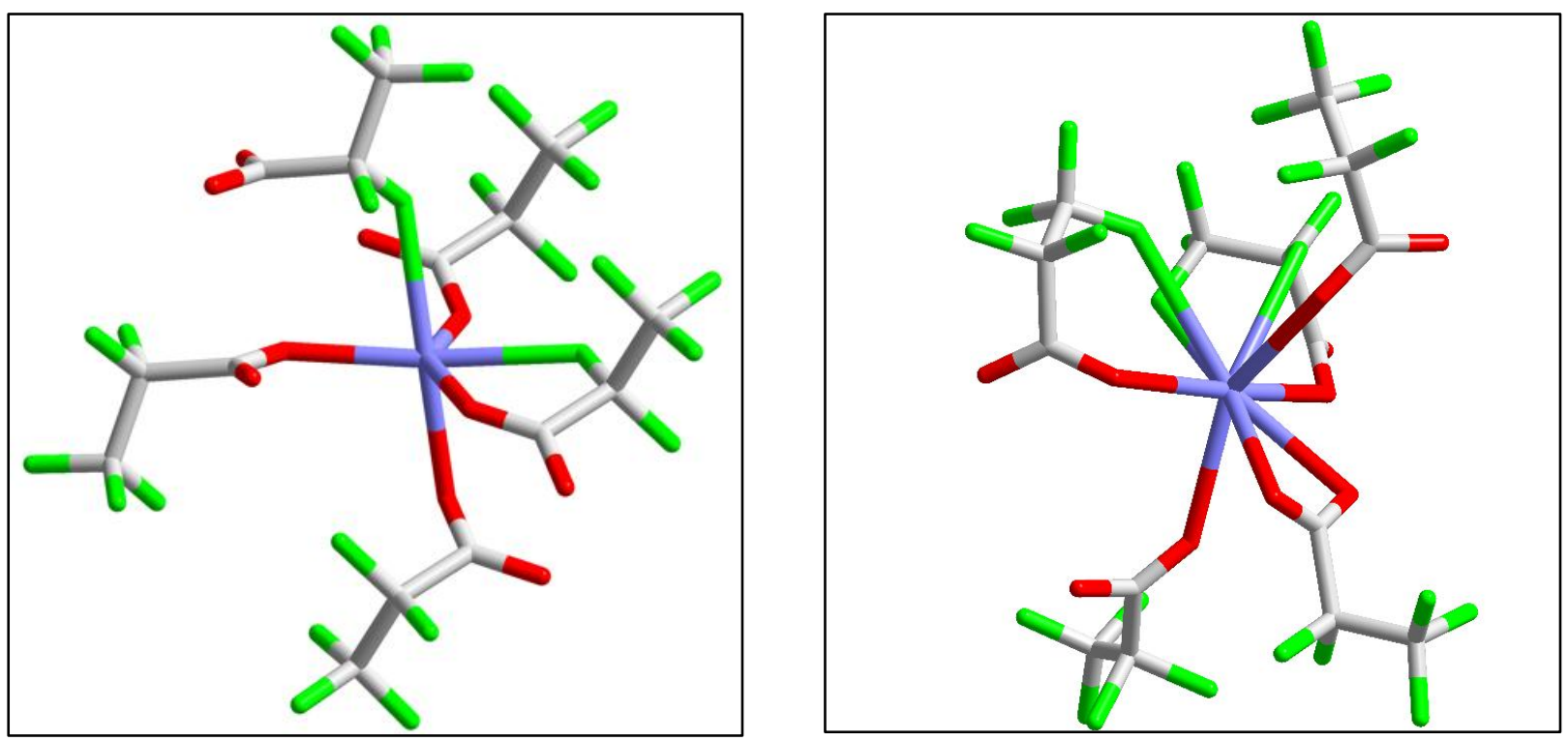

Figure 3. Wire frame representations of sodium pentafluoropropionate around the sodium atom (left side) and potassium pentafluoropropionate around the potassium atom (right side), respectively. Gray $=$ carbon atom, green $=$ fluorine atom, red $=$ oxygen atom, and blue $=$ alkali metal cation.

pentafluoropropionate, these types of short contacts are most often to $\beta$-fluorine atoms. Since the mechanism for the generation of TFE and $\mathrm{CO}_{2}$ from the decomposition of a metal pentafluoropropionate salt would generally be thought of as occurring by a concerted $\beta$ elimination [23], one may wonder if these structural differences also play a role in the potassium salt yielding better results.

\section{Conclusions}

Herein, we report evidence for why potassium pentafluoropropionate prepared from the simple neutralization of pentafluoropropionic acid and potassium hydroxide is the preferred pentafluoropropionate salt for pyrolysis to prepared $\mathrm{TFE} / \mathrm{CO}_{2}$ mixtures in high yield and purity. 
These rationales include (1) an increased overall yields of TFE and $\mathrm{CO}_{2}$, often $98^{+} \%$ yield, (2) a more even control of heat and mass transfer during the pyrolysis, (3) capture of the pyrolysis gases at low temperature under high vacuum, and (4) little to no foaming of the reaction medium with the evolution of gases during the pyrolysis. The thermal and probably the coordination properties of potassium pentafluoropropionate help contribute to its advantages as a starting material for this synthetic method. Evidence for the minor-yield byproducts carbon, C, and carbon tetrafluoride, $\mathrm{CF}_{4}$, is also offered, and these byproducts almost certainly arise from the unwanted disproportionate reaction of TFE under the harsh reaction conditions used.

\section{Experimental}

Disclaimer: The authors make no warranties, expressed or implied, and assume no liability in connection with any use of the information presented in this paper. No one but persons having technical skill in this area of fluorine chemistry should attempt or repeat anything presented herein, and then at their own discretion and risk.

\subsection{Materials}

The following reagents were purchased from the vendors indicated and used as received: $\mathrm{CF}_{3} \mathrm{CF}_{2} \mathrm{C}(\mathrm{O}) \mathrm{OH}$ (SynQuest Labs or Matrix Scientific), $\mathrm{CF}_{3} \mathrm{CF}_{2} \mathrm{C}(\mathrm{O}) \mathrm{OCH}_{2} \mathrm{CH}_{3}$ (SynQuest Labs), (Me) ${ }_{3} \mathrm{SiOK}$ (SynQuest Labs). Technical grade potassium hydroxide $(90+\%)$, as well as other alkali metal and alkaline earth metal hydroxides, were taken from laboratory stock. Diethyl ether was distilled off of sodium metal prior to use. 


\subsection{Methods}

The ${ }^{1} \mathrm{H}-,{ }^{19} \mathrm{~F}$-, and ${ }^{13} \mathrm{C}-\mathrm{NMR}$ spectra were recorded on a JEOL $300-\mathrm{MHz}$ spectrometer using a Young's tube for gaseous samples and normal techniques for solid and liquid samples. ${ }^{1} \mathrm{H}-$ NMR spectra were recorded for substances that do not even have protons in order to double check their purities. IR spectra were recorded on a Thermo Scientific Nicolet iS5 spectrophotometer with either the iD1 Transmission or iD5 ATR option, depending on the physical state of the sample. Gaseous mixtures of $\mathrm{TFE} / \mathrm{CO}_{2}, \mathrm{TFE}$, and $\mathrm{CF}_{4}$ were loaded at 40 Torr (sometimes less) into a $10-\mathrm{cm}$ gas cell with silicon windows, while samples of potassium pentafluoropropionate were placed as dry, fine powders on the diamond crystal of the ATR accessory. GC-mass spectra were obtained on all gaseous samples on a Shimadzu GCMS-QP5000 with a $30 \mathrm{~m}, 0.25 \mu \mathrm{m}$ film Rxi-5HT column, while LC-mass spectrometry data on solids (in methanol) were collected on a Bruker HCT Ultra PTM Discovery System using ESI and the negative ion mode.

Thermogravimetric analyses (TGAs) were run on a TA Instruments Model Q500 under a stream of dry nitrogen; as much as possible, samples were further dried on the instrument in a stream of nitrogen at $100{ }^{\circ} \mathrm{C}$ prior to acquiring the data. Differential scanning calorimetry experiments were carried out in a similar fashion on a TA Instruments Model Q600 SDT. The accelerating rate calorimetry $\left(\mathrm{ARC}^{\circledR}\right)$ experiments were carried in an $\mathrm{ARC}^{\circledR} 2000^{\mathrm{TM}}$ from Arthur D. Little, Inc. using 1-in. o.d. Hastelloy bombs from Tricor Metals Inc. and ca. 0.5-1.5 g of pentafluoropropionate salt samples. Prior to use, the bombs were washed with acetone and deionized water followed by overnight drying in an oven at $120^{\circ} \mathrm{C}$. The "heat-wait-search" mode of operation was used in which a heating rate of $10^{\circ} \mathrm{C} / \mathrm{min}$ with $10^{\circ} \mathrm{C}$ steps making sure that the self-heating range was lower than $0.02{ }^{\circ} \mathrm{C} / \mathrm{min}$. The system was kept adiabatic for both periods of "wait" and "search" [24]. The energy dispersive X-ray analysis (EDAX) were performed on a 
Hitachi S3400 SEM / Oxford X-Max EDX using a beam energy of $10 \mathrm{kV}$. Each solid sample was placed in the sample holder with the aid of copper double-sided adhesive tape.

Bulk reaction products were evaluated by powder X-ray diffraction (XRD) using a Rigaku Ultima IV diffractometer. Well-ground samples were analyzed in Bragg-Brentano geometry using $\mathrm{Cu} \mathrm{K \alpha}(\lambda=1.5406 \AA)$ radiation. Data were collected in 0.02-degree increments from 5-50 degrees in 2-theta at a rate of one degree per minute. Single crystal X-ray diffraction experiments of colorless plate-like crystals were performed at $100 \mathrm{~K}$ using a Bruker D8 Venture diffractometer. The data were collected using phi and omega scans $\left(0.50^{\circ}\right.$ oscillations $)$ with a Mo $\mathrm{K} \alpha(\lambda=$ $0.71073 \AA$ ) microfocus source and Photon 100 detector. Data were processed using the SAINT software program, and corrected for absorption using the SADABS multi-scan technique, both within the Apex3 suite [25]. The structures were solved by intrinsic phasing and subsequently refined by full matrix least squares on $F^{2}$ using the SHELXTL software package [26]. Complete results of the structure refinements, including tables of interatomic distances and angles are included in the Supporting Information.

\subsection{Preparation of $\mathrm{CF}_{3} \mathrm{CF}_{2} \mathrm{C}(\mathrm{O}) \mathrm{O}^{-} \mathrm{K}^{+}$}

(Method A): An amount of $164.0 \mathrm{~g}(1.00 \mathrm{~mol})$ of $\mathrm{CF}_{3} \mathrm{CF}_{2} \mathrm{C}(\mathrm{O}) \mathrm{OH}$ was added drop wise to a solution of $56.1 \mathrm{~g}(1.00 \mathrm{~mol})$ of $\mathrm{KOH}\left(90+\%\right.$ technical grade [27]) dissolved in $300.0 \mathrm{~mL} \mathrm{H}_{2} \mathrm{O}$ cooled in an ice bath. The acid must be added slowly to avoid the mixture warming up rapidly and therefore evaporating away any of the acid. The $\mathrm{pH}$ of the resulting solution was tested, and $\mathrm{CF}_{3} \mathrm{CF}_{2} \mathrm{C}(\mathrm{O}) \mathrm{OH}$ was added until the solution became slightly acidic. After removal of bulk water with a rotavap, the salt was ground to a fine powder with a mortar and pestle, and then dried until 
constant weight at $80-100{ }^{\circ} \mathrm{C}$ under dynamic vacuum at $20-30$ mTorr. A percent yield of $98 \%$ was achieved.

(Method B): A solution of $50 \mathrm{mmol}$ of $(\mathrm{Me})_{3} \mathrm{SiO}^{-} \mathrm{K}^{+}$in $25 \mathrm{~mL}$ of dry diethyl ether was added drop wise to a solution of $50 \mathrm{mmol}$ of $\mathrm{CF}_{3} \mathrm{CF}_{2} \mathrm{C}(\mathrm{O}) \mathrm{OCH}_{2} \mathrm{CH}_{3}$ dissolved in $300 \mathrm{~mL}$ of dry diethyl ether contained in a 1-L, round-bottomed flask under $\mathrm{N}_{2}$ atmosphere. Once the $\left(\mathrm{CH}_{3}\right)_{3} \mathrm{SiO}^{-} \mathrm{K}^{+}$was added, the solution was left stirring overnight. The agitation was removed, and the solution was allowed to stand for a period of 48 hours. The solution was then filtered, and the filter cake was washed thoroughly with dry diethyl ether and dried under vacuum at 20-30 mTorr. A percent yield of $77 \%$ was achieved.

Potassium pentafluoropropionate: ${ }^{19} \mathrm{~F}$ NMR $\left(282 \mathrm{MHz}, \mathrm{D}_{2} \mathrm{O}, \mathrm{CFCl}_{3}\right) \delta-83.2(\mathrm{~s}, 3 \mathrm{~F}), \delta$ $-120.9(\mathrm{~s}, 2 \mathrm{~F}) .{ }^{13} \mathrm{C} \mathrm{NMR}\left(75.46 \mathrm{MHz}, \mathrm{D}_{2} \mathrm{O}, \mathrm{TMS}\right) \delta 107.15\left(\mathrm{tq}, J_{1}=262.1 \mathrm{~Hz}, J_{2}=37.7 \mathrm{~Hz}, C \mathrm{~F}_{2}\right)$, $\delta 118.66\left(\mathrm{qt}, J_{1}=284.7 \mathrm{~Hz}, J_{2}=35.1 \mathrm{~Hz}, C \mathrm{~F} 3\right), \delta 163.45\left(\mathrm{t}, J_{2}=24.5 \mathrm{~Hz}, C=\mathrm{O}\right)$. FT-IR: $(\mathrm{C}=\mathrm{O})$ $1674(\mathrm{~m}), 1408$ (w), 1322 (w), (C-F) 1204 (m), 1150 (s), 1026 (m) cm ${ }^{-1}$. Mass spectrum (ESI', $\mathrm{m} / \mathrm{z}$, ion): $119.0 \quad\left[\mathrm{CF}_{3} \mathrm{CF}_{2}\right]^{-}, \quad 162.9 \quad\left[\mathrm{CF}_{3} \mathrm{CF}_{2} \mathrm{COO}\right]^{-}, \quad 327.0 \quad\left[\left(\mathrm{CF}_{3} \mathrm{CF}_{2} \mathrm{COO}\right)_{2}+\mathrm{H}\right]^{-}, \quad 348.9$ $\left[\left(\mathrm{CF}_{3} \mathrm{CF}_{2} \mathrm{COO}\right)_{2}+\mathrm{Na}\right]^{-}, 364.9\left[\left(\mathrm{CF}_{3} \mathrm{CF}_{2} \mathrm{COO}\right)_{2}+\mathrm{K}\right]^{-}, 534.9\left[\left(\mathrm{CF}_{3} \mathrm{CF}_{2} \mathrm{COO}\right)_{3}+2 \mathrm{Na}\right]^{-}, 550.9$ $\left[\left(\mathrm{CF}_{3} \mathrm{CF}_{2} \mathrm{COO}\right)_{3}+\mathrm{Na}+\mathrm{K}\right]^{-}, 720.9\left[\left(\mathrm{CF}_{3} \mathrm{CF}_{2} \mathrm{COO}\right)_{4}+3 \mathrm{Na}\right]^{-}, 736.8\left[\left(\mathrm{CF}_{3} \mathrm{CF}_{2} \mathrm{COO}\right)_{4}+2 \mathrm{Na}+\mathrm{K}\right]^{-}$, $752.8\left[\left(\mathrm{CF}_{3} \mathrm{CF}_{2} \mathrm{COO}\right)_{4}+\mathrm{Na}+2 \mathrm{~K}\right]^{-}$.

\subsection{General method of preparation of $\mathrm{CF}_{3} \mathrm{CF}_{2} \mathrm{C}(\mathrm{O}) \mathrm{O}^{-} \mathrm{M}^{+}$}

In a similar way as preparing $\mathrm{CF}_{3} \mathrm{CF}_{2} \mathrm{C}(\mathrm{O}) \mathrm{O}^{-} \mathrm{K}^{+}$(Method $\mathrm{A}$ ), other pentafluoropropionate salts can be prepared by neutralizing a solution of the $\mathrm{M}^{\mathrm{n}+}(\mathrm{OH})_{\mathrm{n}}$. For the cases of $\mathrm{Ca}(\mathrm{OH})_{2}$ and $\mathrm{Ba}(\mathrm{OH})_{2}$ that are slightly soluble, the desired amount of base to be neutralized was placed in a beaker, and acid was added until all the base dissolves and the $\mathrm{pH}$ was slightly acidic. After 
removal of bulk water with a rotavap, the salt was dried at $80-100{ }^{\circ} \mathrm{C}$ for $24 \mathrm{~h}$ using a dynamic vacuum at 20-30 mTorr until constant weight. A percent yield of 99\% was achieved.

\subsection{Preparation of tetrafluoroethylene-carbon dioxide $\left(\mathrm{TFE}-\mathrm{CO}_{2}\right)$ mixture}

Further disclaimer: These reactions should only be done in a facility specifically designed to handle TFE safely.

(Method A-from potassium pentafluoropropionate): An amount $202 \mathrm{~g}(1.00 \mathrm{~mol})$ of dry and finely grounded $\mathrm{CF}_{3} \mathrm{CF}_{2} \mathrm{COO}^{-} \mathrm{K}^{+}$salt was placed in a 1-L long-necked, round-bottomed flask. The flask was connected to a 1-Gal Hoke stainless steel cylinder that had been converted into a trap. The outlet port of the cylinder was connected to dynamic vacuum (20-30 mTorr). The flask was heated slowly until reaching $300{ }^{\circ} \mathrm{C}$, during which time a small increase in the vacuum pressure gauge was observed indicating the presence of a non-condensable gas. The heating process was stopped after the pressure in the vacuum gauge once again returned to 20-30 mTorr. The flask was allowed to cool to room temperature again under dynamic vacuum. Often, two or three reaction flasks were connected to a common manifold prior to the collection cylinder/trap. An amount of $141 \mathrm{~g}$ of a mixture of $\mathrm{TFE} / \mathrm{CO}_{2}$ was obtained from the pyrolysis of one batch of potassium pentafluoropropionate representing a percent yield of $98 \%$.

Pyrolysis of smaller quantities of potassium pentafluoropropionate prepared by the silanolate method generally produced $\mathrm{TFE} / \mathrm{CO}_{2}$ in only about $75-80 \%$ yield. For example, $34.0 \mathrm{~g}$ of potassium pentafluoropropionate gave $17.9 \mathrm{~g}$ of a mixture of TFE and $\mathrm{CO}_{2}$. 
(Method B - from sodium pentafluoropropionate): An amount $74.4 \mathrm{~g}(0.400 \mathrm{~mol})$ of dry and finely ground $\mathrm{CF}_{3} \mathrm{CF}_{2} \mathrm{C}(\mathrm{O}) \mathrm{O}^{-} \mathrm{Na}^{+}$salt was placed in a 1-L long-necked, round-bottomed flask. The flask was connected to a 500-mL Hoke stainless steel cylinder, which had been converted into a trap. The outlet port of the cylinder was connected to 20-30 mTorr of dynamic vacuum. The previously dried salts were left overnight at $80^{\circ} \mathrm{C}$ under dynamic vacuum for further drying and leak checking of the system. After the salts had been dried scrupulously, the Hoke cylinder was cooled to liquid nitrogen temperature, and the round-bottomed flask was heated slowly at a rate of $1{ }^{\circ} \mathrm{C} / \mathrm{min}$ until reaching $300{ }^{\circ} \mathrm{C}$. An increase of pressure (from a baseline of $30 \mathrm{mT}$ Torr to 50 mTorr), by the presence of a non-condensable gas, was observed. The heating process was stopped after the pressure in the vacuum gauge once again returned to 30 mTorr. The flasks were left to reach room temperature under dynamic vacuum. A total of $52.6 \mathrm{~g}(0.365 \mathrm{~mol}$ each $)$ of $\mathrm{TFE} / \mathrm{CO}_{2}$ were gained in the Hoke trap cylinder, and a total of $21.6 \mathrm{~g}$ of primarily NaF were left in the round-bottomed flask. The yield calculated from the $\mathrm{TFE} / \mathrm{CO}_{2}$ produced is $91.3 \%$.

In a separate pyrolysis experiment where the sodium pentafluoropropionate salts were heated considerably quicker to $300^{\circ} \mathrm{C}$, a significant decrease in yield was observed. For example, when $99.0 \mathrm{~g}(0.532 \mathrm{~mol})$ of sodium pentafluoropropionate were used, a mass of $44.7 \mathrm{~g}$ remained in the pyrolysis flask, while $53.9 \mathrm{~g}(0.374 \mathrm{~mol}$ each $)$ of primarily $\mathrm{TFE} / \mathrm{CO}_{2}$ remained in the collection trap. The percent yield of $\mathrm{TFE} / \mathrm{CO}_{2}$ was $70.3 \%$.

Tetrafluoroethylene-carbon dioxide: ${ }^{19} \mathrm{~F}-\mathrm{NMR}\left(282 \mathrm{MHz}, \mathrm{CD}_{3} \mathrm{CN}\right) \delta-131.77(\mathrm{~s}, 4 \mathrm{~F}) .{ }^{13} \mathrm{C}-$ NMR (75.46 MHz, gas) $\delta 126.69\left(\mathrm{~s}, C \mathrm{O}_{2}\right), 143.67\left(\mathrm{~m}, C_{2} \mathrm{~F}_{4}\right)$ [28]. FT-IR (gas): $(\mathrm{O}=\mathrm{C}=\mathrm{O}) 2351$ (m), (C-F) 1333 (vs), (C-F) $1194(\mathrm{vs}) \mathrm{cm}^{-1}$ [29]. 
4.6. Scrubbing of carbon dioxide from tetrafluoroethylene-carbon dioxide $\left(\mathrm{TFE} / \mathrm{CO}_{2}\right)$ mixture and reinhibition with D-limonene

Further disclaimer: These reactions should only be done in a facility specifically designed to handle TFE safely.

The experimental setup used for this separation is illustrated in Figure 4. The D-limonene bubbler was a single-ended, 250-mL Hoke cylinder containing approximately $100 \mathrm{~g}$ of Dlimonene. The calcium sulfate scrubber was a double-ended, 500-mL Hoke cylinder completely filled with calcium sulfate. The whole system was checked for leaks, evacuated, and purged with nitrogen three times before the following procedure was carried out.

Two 1-Gal Hoke cylinders that had been made into trap cylinders were connected to a manifold containing a TFE regulator that was adjusted to $50 \mathrm{psig}$. Three in-line orifices $(0.010$ " internal diameter) were placed immediately after the cylinder valve of each cylinder and the other one after the regulator in order to control the flow. The contents of one of $\mathrm{TFE} / \mathrm{CO}_{2}$ cylinder at a time was bubbled at a constant rate of 0.3500 SLM through a stainless steel bubbling stone submersed in an aqueous solution of $\mathrm{KOH}(5 \mathrm{~L}, 40-\mathrm{wt} \%)$ that has previously been placed and degassed inside the 2-Gal stainless steel autoclave shown in Figure 4. Agitation of the caustic solution was kept at a constant rate of $800 \mathrm{rpm}$, while the temperature of the reactor was maintained at $10^{\circ} \mathrm{C}$ by the action of the internal cooling coil that was connected to a cooling machine set at $5{ }^{\circ} \mathrm{C}$. As the TFE bubbled to the surface of the solution, it was carried under reduced pressure through a calcium sulfate desiccator and then through a D-limonene bubbler before being collected in a third 1-Gal stainless steel Hoke cylinder being held at $-70{ }^{\circ} \mathrm{C}$ (dry ice / 
isopropanol bath). Once the pressure of the source cylinder decreased to about $20 \mathrm{psig}$, the main cylinder valve was closed, and the second source cylinder was opened (as observed by an increase of the pressure in the manifold as shown in Figure S40). For the data featured in the graph shown in Figure S40, a total of $757 \mathrm{~g}$ of the gas mixture was taken out of the first cylinder and a total of $738 \mathrm{~g}$ of mixture was taken from the second cylinder to give a total of $1495 \mathrm{~g}$ of $\mathrm{TFE} / \mathrm{CO}_{2}$ that passed through the scrubber. A total of $1007 \mathrm{~g}$ of TFE were collected for a total yield of $97.0 \%$. Further analysis of the TFE by infrared spectroscopy confirmed that all the $\mathrm{CO}_{2}$ had been removed.

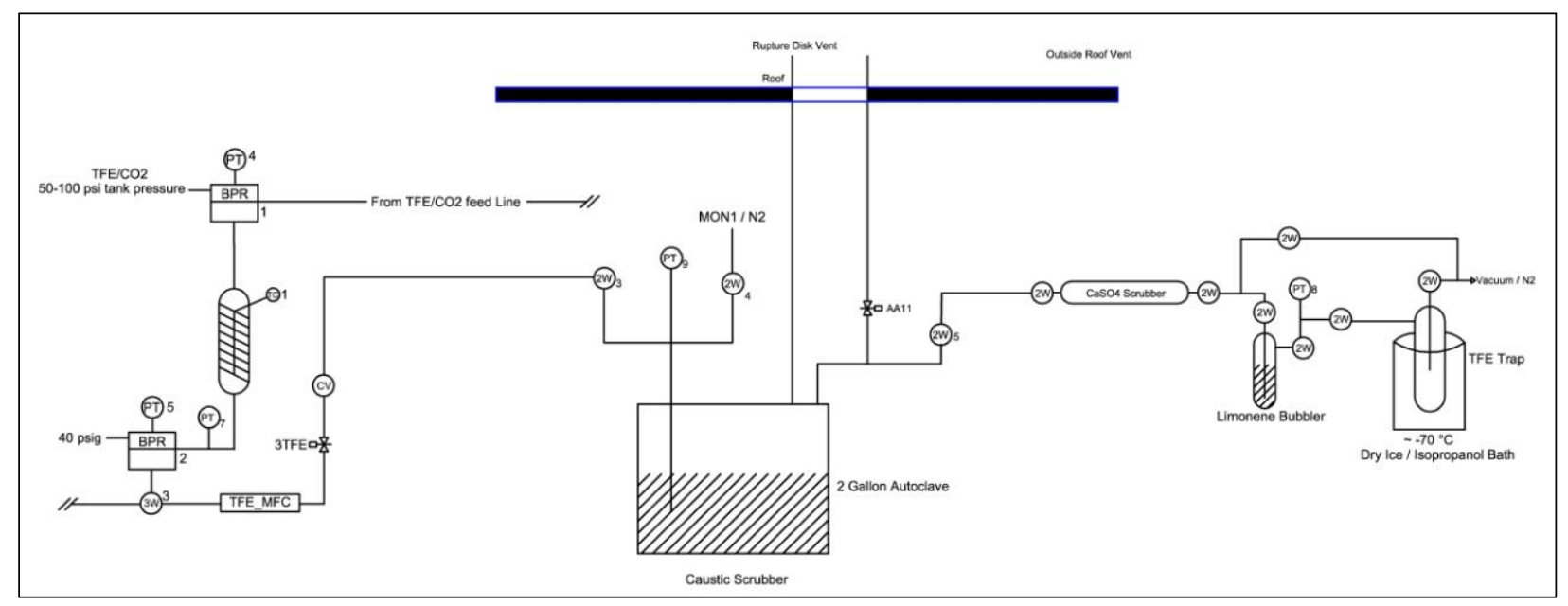

Figure 4. Schematic of 2-Gal autoclave converted into a caustic scrubber [5].

\subsection{Powder and single crystal X-ray diffraction of pentafluoropropionate salts}

Prior to analysis by powder X-ray diffraction, each sample of the pentafluoroproprionate salts, where $\mathrm{M}^{\mathrm{n}+}=\mathrm{Li}^{+}, \mathrm{Na}^{+}, \mathrm{K}^{+}, \mathrm{Cs}^{+}, \mathrm{Mg}^{2+}, \mathrm{Ca}^{2+}$, was finely ground and dried under vacuum at 2030 mTorr for 48 hours. Samples were then placed in a conventional aluminum sample holder and carefully flattened against the surface of the holder in order to provide a flat and level surface. The 
data collections were performed without the possibility to isolate the samples from humidity, so the most hygroscopic samples (lithium and magnesium salts) will have absorbed some water during the data collection period of ca. 45 minutes.

Crystals of both nonhydrated sodium and potassium pentafluoropropionate suitable for single crystal X-ray analysis were grown from slow evaporation of aqueous solutions, while only hydrated crystals of magnesium and calcium pentafluoropropionate have been obtained by the same method. The structures of the latter will be reported separately, as they have no bearing on adding to the understanding of preparing TFE from the pyrolysis of anhydrous pentafluoropropionate salts.

Sodium Pentafluoropropionate: The structure of $\mathrm{CF}_{3} \mathrm{CF}_{2} \mathrm{C}(\mathrm{O}) \mathrm{O}^{-} \mathrm{Na}^{+}$was determined in space group $C 2 / c$, with $a=21.9135(13) \AA, b=6.1114(4) \AA, c=9.1313(5) \AA, \beta=94.738(2)^{\circ}$, with $\mathrm{Z}=8$ for the formula unit $\mathrm{C}_{3} \mathrm{~F}_{5} \mathrm{O}_{2} \mathrm{Na}$. Final refinement values of $\mathrm{R} 1=0.0347$ and $w \mathrm{R} 2=0.0804$ were obtained for 1186 unique reflections with $\mathrm{I}>2 \sigma(\mathrm{I})$.

Potassium pentafluoropropionate: The structure of $\mathrm{CF}_{3} \mathrm{CF}_{2} \mathrm{C}(\mathrm{O}) \mathrm{O}^{-} \mathrm{K}^{+}$was determined in space group $P 2_{1} / n$, with $a=23.4667(16) \AA, b=9.9952(6) \AA, c=25.5061(18) \AA, \beta=107.046(2)^{\circ}$, with $\mathrm{Z}=36$ for the formula unit $\mathrm{C}_{3} \mathrm{~F}_{5} \mathrm{O}_{2} \mathrm{~K}$. Final refinement values of $\mathrm{R} 1=0.0702$ and $w \mathrm{R} 2=$ 0.1650 were obtained for 8747 unique reflections with $\mathrm{I}>2 \sigma(\mathrm{I})$. These crystals were of somewhat lower quality and more weakly diffracting than the Na species, and the structural model indicates some degree of disorder of some of the $\mathrm{CF}_{2}$ and $\mathrm{CF}_{3}$ groups. Where possible, this disorder was included in the model. In other instances, convergence could not be achieved by a disordered model, and the anisotropic displacement parameters of the affected atoms were appropriately restrained. Nevertheless, the resulting refinement is useful for comparison to the sodium analog, particularly regarding the alkali metal coordination. 


\section{Supporting Information}

Multinuclear NMR, FT-IR, and mass spectra, ARC and TGA thermograms, and a plot of pressure versus time from a procedure of scrubbing $\mathrm{CO}_{2}$ from TFE are given in the Supporting Information. Details of the powder and single crystal X-ray diffraction data of both sodium and potassium pentafluoropropionate are also given in the Supporting Information, and the latter have also been deposited in the Cambridge Crystallographic Data Centre as CCDC 1495456-1495457, respectively.

\section{Acknowledgements}

We acknowledge Prof. Dr. Andreas Kornath and Dr. Alexander Kaufmann (LudwigMaximilians-Universität München, München, Germany) for their helpful advice on this project. We also thank Dr. Taghi Darroudi (Clemson University, 91 Technology Drive, Anderson, SC 29625, USA) for his help with conducting the EDAX experiments. We acknowledge the help from Dr. Qiaoli Liang (University of Alabama, Box 870336, Tuscaloosa, AL 35487, USA) for her help with the LC-mass spectrometry experiments. JST acknowledges the National Science Foundation (CHE-1124859) and the U.S. Department of Energy, Basic Energy Sciences (DEFG02-05ER15718) for financial support. We also thank Dr. Christopher P. Junk for helpful discussions. 


\section{References}

[1] (a) R. J. Plunkett, The history of polytetrafluoroethylene: discovery and development, in: R. B. Seymour, G. S. Kirschenbaum (Eds.), High Perform. Polym., Proc. Symp., 1986, pp. 261266; (b) G. B. Kauffman, Teflon - 50 slippery years, in: Educ. Chem., 1988, 25, 173; (c) S. Ebnesajjad, Fluoroplastics, Volume 1 - Non-Melt Processible Fluoroplastics, William Andrew Publishing, NY, 2000, pp. 23-30.

[2] S. Ebnesajjad, Fluoroplastics, Volume 2: Melt Processable Fluoroplastics, William Andrew Publishing, NY, 2002, pp. 9-12.

[3] (a) T. Okada, M. Saito, K. Hayamizu, Perfluorinated Polymer Electrolyte Membranes for Fuel Cells, Nova Science Publishers, New York, 2008; (b) V. Arcella, L. Merlo, R. Pieri, P. Toniolo, F. Triulzi, M. Apostolo, "Fluoropolymers for Sustainable Energy," in: D. W. Smith, Jr., S. T. Iacono, S. S. Iyer (Eds.), Handbook of Fluoropolymer Science and Technology, John Wiley and Sons, New York, 2014, Chapter 17, pp. 393-412.

[4] (a) F. B. Downing, A. F. Benning, R. C. McHarness, Pyrolysis of Chloro-Fluoro Alkanes, U.S. Patent 2,551,575, May 8, 1951; (b) H. Voigt, R. Freudenreich, Process for the Production of Pure Tetrafluoroethylene, U.S. Patent 4,898,645, Feb 6, 1990; (c) P. B. Chiney, P. D. Sunavala, Thermodynamics and Kinetics for the Manufacture or Tetrafluoroethylene by the Pyrolysis of Chlorodifluoromethane, Ind. Eng. Chem. Res. 26 (1987) 1340-1344; (d) E. Broyer, A. Y. Bekker, A. B. Ritter, Kinetics of the Pyrolysis of Chlorodifluoromethane, Ind. Eng. Chem. Res. 27(1988) 208-211; (e) D. J. Sung, D. J. Moon, S. Moon, J. Kim, S.-I. Hong, Catalytic Pyrolysis of Chlorodifluoromethane over Metal Fluoride Catalysts to Produce Tetrafluoroethylene, Appl. Catal. A-Gen. 292 (2005) 130-137; (f) G. L. Bauer, J. D. Weigelt, 
K. Hintzer, G. Loehr, W. Schwertfeger, A. A. Ponelis, Process for Manufacturing Fluoroolefins, U.S. Patent 6,919,015, Jul 19, 2005 and references therein.

[5] D. A. Hercules, D. D. DesMarteau, R. E. Fernandez, J. L. Clark, Jr., J. S. Thrasher, Evolution of Academic Barricades for the Use of Tetrafluoroethylene (TFE) in the Preparation of Fluoropolymers, in: D. W. Smith, Jr., S. T. Iacono, S. S. Iyer (Eds.), Handbook of Fluoropolymer Science and Technology, John Wiley \& Sons, Inc., Hoboken, NJ, 2014, Chapter 18, pp. 413-431 and references therein.

[6] (a) T. S. Sayler, K. T. Tice, M. A. Beg, R. E. Fernandez, J. S. Thrasher, Preparation of Low Equivalent Weight Perfluorinated Ionomers with Water Insolubility, Polymer Preprints (American Chemical Society, Division of Polymer Chemistry) 53 (2012) 39-40; (b) T. S. Sayler, Ph.D. Dissertation, Preparation of Perfluorinated Ionomers for Fuel Cell Applications, University of Alabama, 2012.

[7] (a) Yu. I. Babenko, Ya. A. Lisochkin, V. I. Poznyak, Explosion of tetrafluoroethylene during nonisothermal polymerization, Combustion, Explosion, and Shock Waves, 29 (1993) 603609; (b) A. Reza, E. Christiansen, A Case Study of a TFE Explosion in a PTFE Manufacturing Facility, Process Safety Progress 26 (2007) 77-82; (c) F. Ferrero, R. Meyer, M. Kluge, V. Schröder, T. Spoormaker, Self-Ignition of Tetrafluoroethylene Induced by Rapid Valve Opening in Small Diameter Pipes, J. Loss Prevent. Proc. 26 (2013) 177-185; (d) F. Ferrero, R. Meyer, M. Kluge, V. Schröder, T. Spoormaker, Study of the Spontaneous Ignition of Stoichiometric Tetrafluoroethylene-Air Mixtures at Elevated Pressures, J. Loss Prevent. Proc. 26 (2013) 759-765; (e) F. Ferrero, M. Beckmann-Kluge, T. Spoormaker, V. Schröder, On the Minimum Ignition Temperature for the Explosive Decomposition of Tetrafluoroethylene on Hot Walls: Experiments and Calculations, J. Loss Prevent. Proc. 25 
(2012) 293-301; (f) F. Ferrero, R. Zeps, M. Beckmann-Kluge, V. Schröder, T. Spoormaker, Analysis of the Self-Heating Process of Tetrafluoroethylene in a $100-\mathrm{dm}^{3}$-Reactor, J. Loss Prevent. Proc. 25 (2012) 1010-1017.

[8] (a) G. Puts, P. Crouse, B. Ameduri, Thermal Degradation and Pyrolysis of Polytetrafluoroethylene, in: D. W. Smith, Jr., S. T. Iacono, S. S. Iyer (Eds.), Handbook of Fluoropolymer Science and Technology, John Wiley \& Sons, Inc.: Hoboken, NJ, 2014, Chapter 5, pp. 83-106; (b) J. Zhu, B.-H. Wang, D.-Z. Liu, Synthesis of 1,2Diiodotetrafluoroethane with Pyrolysis Gas of Waste Polytetrafluoroethylene as Raw Material, Green Chem. 15 (2013) 1042-1047; (c) I. J. van der Walt, H. W. J. P. Neomagus, J. T. Nel, O. S. L. Bruinsma, P. L. Crouse, A Kinetic Expression for The Pyrolytic Decomposition of Polytetrafluoroethylene, J. Fluorine Chem. 129 (2008) 314-318; (d) P. S. Bhadury, S. Singh, M. Sharma, M. Palit, Flash pyrolysis of polytetrafluoroethylene (teflon) in a quartz assembly, J. Anal. Appl. Pyrolysis 78 (2007) 288-290; (e) E. Meissner, A. Wróblewska, E. Milchert, Technological parameters of pyrolysis of waste polytetrafluoroethylene, Polym. Degrad. Stab. 83 (2004) 163-172; (f) B. Baradie, M. S. Shoichet, Synthesis of Fluorocarbon - Vinyl Acetate Copolymers in Supercritical Carbon Dioxide: Insight into Bulk Properties, Macromolecules 35 (2002) 3569-3575; (g) C. M. Simon, W. Kaminksy, Chemical recycling of polytetrafluoroethylene by pyrolysis, Polym. Degrad. Stab. 62 (1998) 1-7; (h) R. J. Hunadi, K. Baum, Tetrafluoroethylene: A Convenient Laboratory Preparation, Synthesis 1982 (1982) 454-454; (i) A. Bezuidenhoudt, P. W. Sonnendecker, P. L. Crouse, Continuous Depolymerization of PTFE: Determining Optimum Operating Conditions, $1^{\text {st }}$ South African Fluorine Symposium (SAFS 2016), Cape Town, South Africa, Feb. 14-18, 2016; OR34; (j) L. Grové, P. L. Crouse, Synthesis and 
Characterization of Sodium Perfluoropropanoate, $1^{\text {st }}$ South African Fluorine Symposium (SAFS 2016), Cape Town, South Africa, Feb. 14-18, 2016; PP10.

[9] D. J. Van Bramer, M. B. Shiflett, A. Yokozeki, Safe Handling of Tetrafluoroethylene, U.S. Patent 5,345,013, Sep. 6, 1994.

[10] Chemours Home, FluoroIntermediates, Products \& Services, TFE, Tetrafluoroethylene - Safe Supply ${ }^{\mathrm{TM}}$, https://www.chemours.com/FluoroIntermediates/en_US/products/olefin_tfe.html (accessed June 28, 2016).

[11] (a) L. J. Hals, T. S. Reid, G. H. Smith, Jr., The Preparation of Terminally Unsaturated Perfluoro Olefins by the Decomposition of the Salts of Perfluoro Acids, J. Am. Chem. Soc. 73 (1951) 4054-4054; (b) J. D. LaZerte, L. J. Hals, T. S. Reid, G. H. Smith, Pyrolyses of the Salts of the Perfluoro Carboxylic Acids, J. Am. Chem. Soc. 75 (1953) 4525-4528; (c) L. J. Hals, T. S. Reid, G. H. Smith, Process of Making Perfluoro Olefins, U.S. Patent 2,668,864, Feb. 9, 1954.

[12] (a) R. N. Haszeldine, The Reactions of Metallic Salts of Acids with Halogens. Part III. Some Reactions of Salts of Fluorohalogenoacetates and of Perfluoro-acids, J. Chem. Soc. (1952) 4259-4268; (b) R. N. Haszeldine, K. J. Leedham, The Reactions of Fluorocarbon Radicals. Part IX. Synthesis and Reactions of Pentafluoropropionic Acid, J. Chem. Soc. (1953) $1548-1552$.

[13] A. Kornath, A. Kaufmann, Ludwig-Maximilians-Universität München, private communication, July 2007.

[14] A. V. Matsnev, S.-Y. Qing, M. A. Stanton, K. A. Berger, G. Haufe, J. S. Thrasher, Pentafluorosulfanyldifluoroacetic Acid: Rebirth of a Promising Building Block, Org. Lett. 16 (2014) 2402-2405. 
[15] (a) B. L. Chenard, E. D. Laganis, Preparation of Anhydrous Organic Acid Salts, U.S. Patent 4,723,016, Feb 2, 1988; (b) E. D. Laganis, B. L. Chenard, Metal Silanolates: Organic Soluble Equivalenets for $\mathrm{O}^{-2}$, Tetrahedron Lett. 25 (1984) 5831-5834; (c) M. Lovrić, I. Cepanec, M. Litvić, A. Bartolinčić, V. Vinković, Scope and Limitations of Sodium and Potassium Trimethylsilanolate as Reagents for Conversion of Esters to Carboxylic Acids, Croat. Chem. Acta 80 (2007) 109-115.

[16] E. C. Kempen, J. S. Brodbelt, R. A. Bartsch, Y.-C. Jang, J. S. Kim, Investigations of Alkali Metal Cation Selectivities of Lariat Ethers by Electrospray Ionization Mass Spectrometry, Anal. Chem. 71 (1999) 5493-5500.

[17] Matheson Gas Data Handbook, $5^{\text {th }}$ ed.; Matheson Gas, 1971.

[18] (a) NIST, National Institute of Standards and Technology. Chemistry WebBook. Tetrafluoromethane. Infrared Spectrum. Gas Phase Spectrum. http://webbook.nist.gov/cgi/cbook.cgi?ID=C75730\&Units=SI\&Type=IR-

SPEC\&Index=1\#IR-SPEC (accessed July 15, 2016). (b) NIST, National Institute of Standards and Technology. Chemistry WebBook. Ethene, tetrafluoro-. Infrared Spectrum. Gas Phase Spectrum. http://webbook.nist.gov/cgi/cbook.cgi?ID=C116143\&Units=SI\&Type=IRSPEC\&Index=1\#IR-SPEC (accessed July 15, 2016).

[19] (a) NIST, National Institute of Standards and Technology. Chemistry WebBook. Tetrafluoromethane. Mass spectrum (electron ionization). http://webbook.nist.gov/cgi/cbook.cgi?ID=C75730\&Units=SI\&Mask=200\#Mass-Spec (accessed July 15, 2016). (b) NIST, National Institute of Standards and Technology. 
Chemistry WebBook. Ethene, tetrafluoro-. Mass spectrum (electron ionization). http://webbook.nist.gov/cgi/cbook.cgi?ID=C116143\&Units=SI\&Mask=200\#Mass-Spec (accessed July 15, 2016).

[20] R. Steudel, Chemistry of the Non-Metals; Walter de Gruyter: Berlin, 1977; pp 68-69.

[21] (a) G. Sugihara, M. Hisatomi, Roles of Counterion Binding in the Micelle Formation of Ionic Surfactants in Water, J. Jpn. Oil Chem. Soc. 47 (1998) 661-716; (b) R. Haque, Nuclear Magnetic Resonance Study of Micelle Formation in Sodium Perfluorocaprylate and propionate, J. Phys. Chem. 72 (1968) 3056-3059; (c) C. E. McNamee, M. Matsumoto, P. G. Hartley, P. Mulvaney, Y. Tsujii, M. Nakahara, Interaction Forces and Zeta Potentials of Cationic Polyelectrolyte Coated Silica Surfaces in Water and in Ethanol: Effects of Chain Length and Concentration of Perfluorinated Anionic Surfactants on Their Binding to the Surface, Langmuir 17 (2001) 6220-6227.

[22] An accessory for collecting powder XRD data was recently obtained for our new diffractometer, so in the future, where necessary, we will be able to collect powder data on sealed samples in order to exclude moisture.

[23] R. D. Chambers, Fluorine in Organic Chemistry, Blackwell Publishing, Oxford, UK, 2004, pp. 144-146.

[24] L. Sun, A. Waterfeld, J. S. Thrasher, A Modified Accelerating Rate Calorimeter (ARC ${ }^{\circledR}$ ) with Capabilities for Handling Gaseous Samples under Vacuum or an Inert Atmosphere, J. Fluorine Chem. 27 (2006) 1436-1439.

[25] M. Adam, Bruker AXS Announces Next-Generation Platform for X-ray Crystallography, May 12, 2015, https://www.bruker.com/products/x-ray-diffraction-and-elemental- 
analysis/news-events-x-rayelemental/news/single-view/article/bruker-axs-announces-nextgeneration-platform-for-x-ray-crystallography.html (accessed July 14, 2016).

[26] G. M. Sheldrick, A Short History of SHELX, Acta Cryst. A64 (2008) 112-122.

[27] The two main impurities in technical grade $\mathrm{KOH}$ are water and $\mathrm{K}_{2} \mathrm{CO}_{3}$, neither of which has an adverse affect on the yield of potassium pentafluoropropionate (cf. [12b]). Duda Diesel Material Safety Data Sheets and Standard Certificate of Analysis. Grades of Chemicals. http://www.dudadiesel.com/sheets.php (accessed July 15, 2016).

[28] (a) R. Ditchfield, P. D. Ellis, ${ }^{13}$ C NMR Chemical Shifts for Fluoroethylenes and Fluoroacetylenes, Chem. Phys. Lett. 17 (1972) 342-344; (b) J. H. Kühn-Velten, G. Hägele, W. Fuss, P. Hering, M. M. Ivanenko, Carbon Isotopomers of Tetrafluoroethylene: LaserInduced Synthesis and NMR Spectroscopic Characterization, Magn. Reson. Chem. 40 (2002) $77-80$.

[29] P. Torkington, H. W. Thompson, The Infra-red Spectra of Fluorinated Hydrocarbons. I. Trans. Faraday Soc. 41 (1945) 236-245. 


\section{Graphical Abstract - Pictogram}

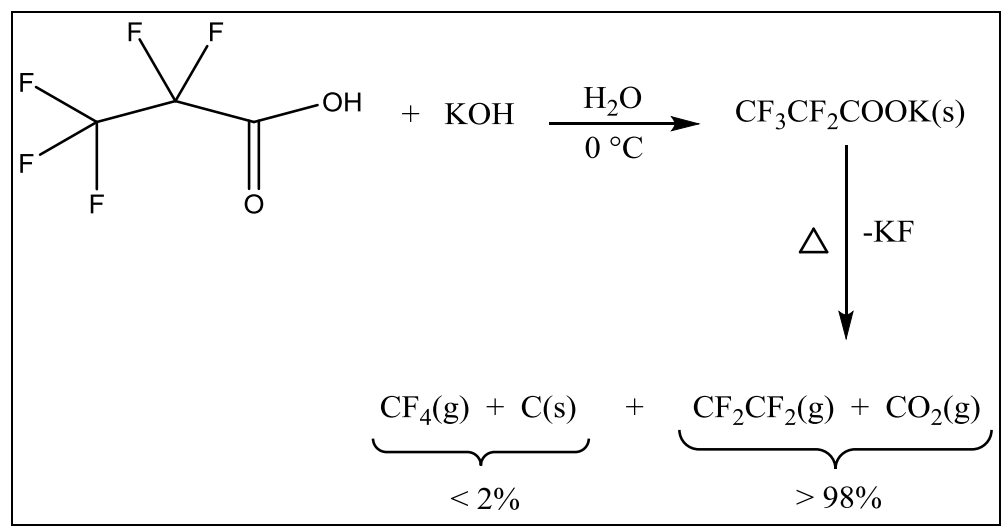

